\title{
Sustainable approaches to nature in traditional architectural space, their application in the teaching of architecture and interior design
}

\author{
Thi Thu Thuy $\mathrm{Vo}^{1, *}$ \\ ${ }^{1}$ Ho Chi Minh City University of Architecture, 27 Đặng Tất, Tân Định Ward, District 1, HCM City, \\ Vietnam
}

\begin{abstract}
In the world in general and in Vietnam in particular, consequences of air pollution and climate change and needs for sustainable environment have recently led to the necessity of the approach to "sustainable development". Vietnamese traditional architecture, rich in humanity and harmonization with nature, possesses a wealth of experience in constructing residential spaces and coping with nature, whose approaches have still retained their values up until this age, deserving a deeper look at modern application. The employment and application of traditional values in sustainable approaches to nature have a significant meaning in the teaching of architecture and arts. In this article, we will discuss values and experience from the process of studying approaches to nature in traditional architecture in order to apply them to modern issues and to the training of spatial designers and interior designers in Ho Chi Minh City University of Architecture.
\end{abstract}

\section{Introduction}

The trends of worldwide integration, globalization and sustainable development have created multiple opportunities for countries to advance their economies and cultures, and at the same time, present to those countries various challenges, among which climate change and anthropogenic habitat destruction are counted as two of the most serious problems. Vietnamese traditional architecture, rich in humanity and harmonization with nature, possesses a wealth of experience in constructing residential spaces and coping with nature, whose approaches have still retained their values up until this age, deserving a deeper look for modern application.

The world in general and Vietnam in particular have faced detrimental effects from air pollution and climate change, and the need for a sustainable environment has driven us to the concept of "sustainable development". Chronologically, the world has witnessed the trends of Bio-climatic Architecture in 1960s, Energy Conservation Architecture in 1970s, Intelligent Building in 1980s, Ecological Design or Green Architecture in 1990s. Architecture for Sustainable Development was materialized and developed after the Earth Summit for Sustainable Development in Rio de Jainero in 1992. It was the latest and most

\footnotetext{
* Corresponding author: thuylylyvo @yahoo.com
} 
comprehensive event for architectural trends, in terms of concepts, solutions, and in related aspects.

Vietnam, facing numerous issues from environment pollution, from natural disasters resulting from climate change, and from the over-exploitation of natural resources, has paid particular attention to sustainable development. The Government has issued "Guidance and Strategies for Sustainable Development in Vietnam" (Vietnam's 21 ${ }^{\text {st }}$ Agenda) in 2004 and "Sustainable Development Strategies" for the period 2011-2020 in 2012 in order to develop sustainably and effectively, in tandem with social equality and progress, environmental and natural resource preservation, social and political stability, and with the defense of national independence, sovereignty, unity, and territorial integrity.

In this article, we will discuss values and experience from the process of studying approaches to nature in traditional architecture, as to apply them to modern issues and to the training of spatial designers and living space designers in Ho Chi Minh City University of Architecture.

\section{Lessons from sustainable approaches to nature and to the environment in Vietnamese traditional architecture}

Vietnamese traditional architecture in general and Vietnamese ancient houses in particular possess unique characteristics and nuances, resulting from many factors, varying from region to region and from the way people in different locations behave with their surroundings, showcasing how people in the past adapted to nature and environment in traditional architectural space, leaving behind for Vietnamese people valuable lessons in architecture and construction, in relation with today's sustainable and ecological development trends.

The concept "Nature" is an assemble of existing natural conditions that humans cannot affect such as geography, climate, creatures, atmospheres... together with physical conditions necessary for the existence of human beings, including those that humans can influence and create (artificial nature). Nature is constituted from a variety of elements. Those elements are terrestrial resources such as soil, water, sunlight, wind, floras, faunas... at a particular locale. The elements exist and develop according to their own rules, constantly exchanging materials and energy, creating a full-fledged, unified physical system, continuously exerting their influences on the living environment and residential space. Thus, each region has its own architectural features. "...nature itself cannot regulate the framework of a house. It is the human being who clearly perceives nature and creates the framework of his house in his own country" (Nguyễn Trực Luyện (1977), From Old Thatched Houses, Hanoi Cultural Publishing House, pg. 24). The above natural factors are the foundations for experience in sustainable approaches in this article. 


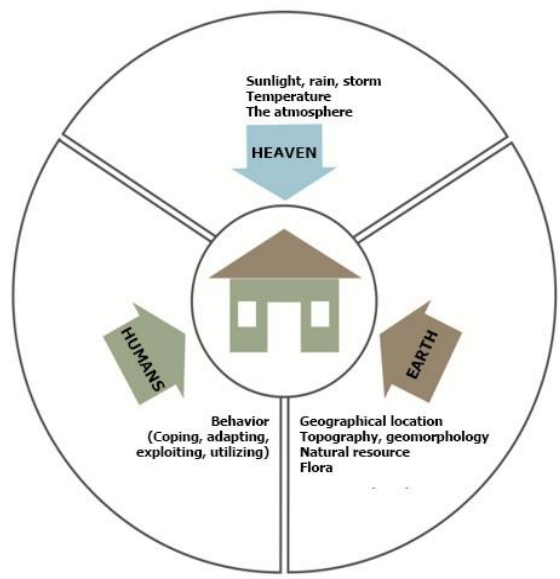

Fig. 1. Factors influencing the organization of architectural space.

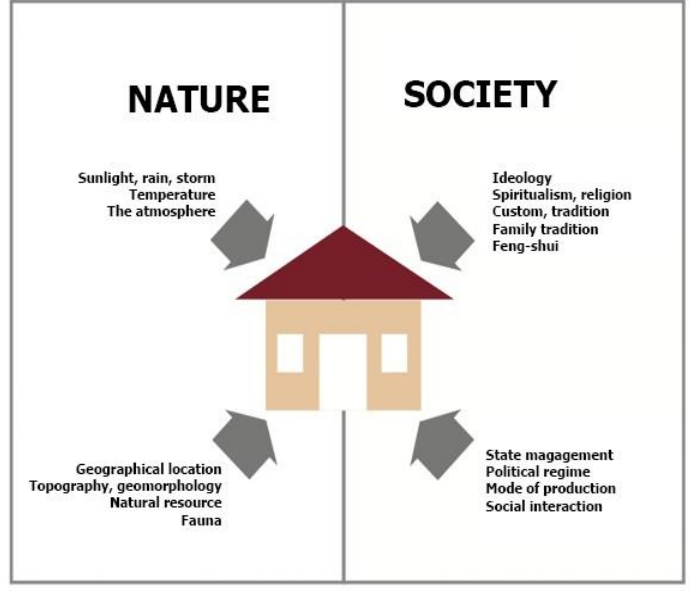

Fig. 2. Natural and social factors influencing architectural space.

Through our surveys and studies of approaches to nature in traditional architectural space, we have arrived at certain conclusions that we consider probably useful in raising our awareness and applicable in the field of interior design training that we are currently active in. The following points are unique behavioral patterns to nature, obtained from studies of Vietnamese people's residential spaces:

\section{Exploiting and utilizing effectively and moderately existing natural potentials}

The soil factor is experience in adapting to and taking advantage of topography, terraneous features and natural resources to gain a deeper understanding of the earth, to build the most suitable foundation in the most appropriate direction, and to make full use of the good "qi" from nature, as the saying goes: "Good land attract many birds". The precincts of a traditional house is not usually large; thus, much consideration is given to the effective and harmonious arrangement of the main house, the auxiliary house (including the kitchen and storage), agricultural productions, and the extra work of the family, consisting of the yard, the vegetable garden, greenery, the barn, the fish pond... [8, pg. 68].

The water factor governs and tremendously influences the habitat, habits and consciousness and feelings of Vietnamese people, who opt for areas close to rivers with thriving prospect as their settlements. From the reality of a fluvial lifestyle or from experience in coping with, controlling and conquering waters of rivers, lakes, ponds, and wells...people have learned to expand the water surface to successfully harness benefits from nature, not only to meet daily needs but also to keep the ecology in balance. This balance is conveyed through the concept of yin and yang in architecture - the ground (high) is regarded as yang, the water surface (low) is regarded as yin. The pond represents an organic, ecological cycle of soil - water - greenery and humans. The people have masterfully made use of the topography of lowlands and the natural environment to turn disadvantages (moving the ground from low to high) into strengths (heightening floors, building fish ponds), and to use nature to regulate nature itself (using water surface as a cooling device, as a climate regulator, to provide green space and food, and to construct exterior landscapes...).

The climate factor. Vietnamese people have distilled much experience for choosing the ground and the direction for a new house, and for avoiding harsh sunlight and storms. In Vietnam, South is the most favored direction for a house. There are various solutions to cope 
with a constantly changing environment: multi-layered roofs, widely-spaced columns and foot of the wall, wide verandas, fixed or movable sunscreens, pergolas on the front of the house and hedges around the house to block sunlight. Doors to different compartments in a house are kept open all the time for the air to flow continuously, resulting in airiness and good lighting. In addition, high betel trees with narrow canopies are grown in the front yard to let in good winds while short banana trees with big canopies are planted behind the house to keep the soil moist and to prevent cold winds...The Mekong Delta in Vietnam is characterized with watery habitats. As a result, the house in this area is built on wetlands and solutions for humidity and flooding in architecture are called for, creating distinctive nuances of the Southern architecture.

The flora factor: From an ecological perspective, every living organism (humans, plants, livestock...) is considered a biome, a cycle of materials that tends to remain balanced and stable.

Plants in a house's garden: Plants are important economic assets, which work with soil, water, sunlight, wind to regulate climate, fostering the harmony between architecture and environment. In addition to the main house, components such as gates, ponds, partition walls, pergolas, and plants are consciously selected to suit climatic conditions, topography, architectural styles, colors, the scale of the building....and are orderly planned and trimmed into particular shapes to serve as a mediator between the interior space and the garden-scape, as a connection to nature. The main house is often humbly built under the canopy, mirroring itself onto the water surface, surrounded by meandering pathways in an amicably verdant landscape. The house shows a sustainable and harmonious pattern of behavior, limiting intervention with and destruction of the naturalness of natural environments.

Plants as construction materials: Vietnamese traditional architecture is mainly based on abundant sources of plants, readily available in nature. The folk house often makes use of wood, rattan, bamboo, neohouzeaua (nứa), palm leaves, coconut leaves... which can be found in many regions. Woody trees such as jackfruit, bead-tree, bamboo... are also widely used to make ploughs, bailers, and knitting materials for traditional containers and drying implements (nong, nia, dần, sàng) and many other daily items. The author Hoàng Đạo Kính has succinctly put it: "...the space of a Vietnamese traditional house is developed according to a closed diagram. Life also moves on according to a closed diagram. The entrance and the exit occupy the same spot. All waste decomposes on the spot or out in the field. Architecture is almost certainly organic, foundation-less, and self-erasing. Nature has been utilized for thousands upon thousands of years, and still it suffers very little damage" (Hoàng Đạo Kính (2012), Culture and Architecture, Hanoi Knowledge Publishing House, pg.191).

\section{Coping with and improving natural limitations}

There are copious natural phenomena and factors affecting the life of Vietnamese people, and the people, through many generations, have accumulated an accordingly high amount of wisdom in dealing with, making use of, and adapting to such conditions, all of which are a treasure trove of experience, well-proven in the construction of houses.

Coping with disadvantageous natural-ecological conditions

Nature brings not only benefits to the people, but also potential disasters and drawbacks that call for solutions and rectification by means of wisdom and inborn capacity. With the hope to conquer nature while creating living spaces, Vietnamese people all over the country have shown flexible adaptations in farming and agricultural production habits (building dykes, ponds, canals, trenches...), in settlement traditions (settling near rivers), in building houses (houses on stilts, floating houses...). For instance, in the Mekong Delta, inhabitants carry out their life on rivers and canals in boat-houses. With simple, lightweight construction materials, those houses are built with doors open directly to the open space, to get the best 
out of sunlight, to provide sufficient airiness, to combat humidity and heat. Without heavy storms, the roof is lightweight and has high slopes to let water run down quickly.

Improving the ecosystem via spatial arrangement and architectural form

Spatial arrangement: The main house of a family usually occupies the central spot in the precincts, detached from the auxiliary house. The plan of a Northern house is often rectangular, with the length 1.5 or 2 times the width. The house is divided into compartments, with three compartments and two lean-tos, or five compartments and two lean-tos; the compartments are interconnected, creating a continuous space, with verandas running along the front of the house. To the direction of cool winds, doors are kept open while in the direction of cold winds, they are closed and low trees with wide canopies are grown. In stormy areas, square houses with low roofs are built. In areas receiving Foehn winds, wide verandas with bamboo screens or shades are put into use. In lowlands affected by floods, floors are heightened and houses on stilts are constructed.

Architectural structure: The house, built of wood, assembled from columns, girders, and roofs, can stay securely fixed when under the effect of external forces such as fires. The roof in a traditional house makes up a considerable proportion of the building, often exceeding half the of the front of the house, forming verandas that act as intermediary space, joining functions like the complete blocking of rain and harsh sunlight, the prevention of humidity, the reception of cool winds for airiness, the provision of a tie to nature outside, all of which work in relation to a hot and humid environment. Walls right under the roof and ridges are built with narrow air holes for ventilation. There are many components to create shade and regulate temperature such as louvers, blinds, decorative plants, rockeries, ponds, and especially wide verandas and bamboo sunscreens. There is a profusion of doors and windows in a house erected to the direction with cool winds and they are kept open in the front of the house. Doors are accompanied by windows with baluster-shaped grids for better ventilation and natural lighting, and less heat. The floor is several steps higher than the yard, and doors are a little higher than the floor for ventilation which helps dries the floor.

Materials: Throughout history, the people have employed locally available material for their houses: wood, rattan, bamboo, neohouzeaua (nứa), palm leaves, coconut leaves for components such as wooden, especially bead-tree, columns and collar and strutting beams. Well-off families value high-prized woods from the forest, in particular the four "iron" woods (tứ thiết): Pterocarpus macrocarpus (đinh), Erythrophleum fordii (lim), Madhuca pasquieri (sến), Vatica dipterocarpaceae (táu). More economically, trees from the Canarium genus (trám), beech, oak, talauma, and Fagraea fragrans (trai) can be harvested from the garden or around the village. They are often carved with decorative details. Roofs are thatched with straw, palm and coconut leaves. Floors are covered with earthenware tiles or terra-cottas. With rudimentary techniques, the craftsman can still transform common materials through ingenious combinations and surface treatments. Slits and holes help to combat harsh sunlight, humidity, temperature and aid ventilation, durability and load-bearing capacity, especially in summer. In winter, such environmentally and ecologically friendly solutions help retain heat, and tackle other natural climatic disadvantages.

The way Vietnamese people deal with climatic influences via house architecture demonstrates flexibility in perception and solution, making use of favorable conditions to work with difficulties, turning drawbacks into strengths. A life in peace means a harmonious approach to nature, a life in and with nature, following its rules, finding benefits in predicaments, accepting that nature cannot be overturned.

Approach to nature via religion and spirituality

In the flow of Southeast Asian cultures, Eastern perspectives on philosophy can be counted among the most influential ideologies on the the Vietnamese people's outlook on constructing residential space. Heaven-Earth-Humans are the unity of nature-architecturehuman beings. The traditional space has applied feng-shui into the building to meet functions, 
to fit habits and to harmonize with nature and Heaven, avoiding potential risks that may break the well-established balance. [9, pg. 143-145]

- The philosophies of Yin-Yang and Wu Xing demonstrate the harmony between humans and their habitats (living and working places), the balance in the creation of everything, which humans have employed in all aspects of life, particularly in the construction of residential space. The space consists of yards and gardens, roofs of double tiles. Components of a house are linked on the same yin-yang balance, striving for a yin-yang consonance, directly palpable to the sense. Architectural opposites such as solid-empty, strong-light, dense-sparse, bright-dark, straight-curvy, high-low... are utilized and regulated harmoniously according to yin and yang, never falling out of rules of nature.

- Folk feng-shui: The study of feng-shui supports solutions to identify fortes and weaknesses of a location to shield humans from health risks and to provides quality living conditions to a house. Feng-shui is spirituality, habits and traditions which, if used correctly, can boost the "qi" flow and bring good fortune. Garden-houses in Huế are put up in the principle of "tiền án hậu chẩm" (well-covered in the front and the back), "tả thanh long, hữu bạch hổ" (literally: green dragon on the left, white tiger on the right; in practice: a mountain or hill on the left, most preferably also in the east, and another lower mountain or hill on the right), "long mạch" (an auspicious locale with influence on humans' fate), "minh đường" (a patch of ground or a pond in front of a house, receiving much natural sunlight), "tứ phương quần tụ" (the converging point of all four directions, signifying good fortune), "vạn vật biến hóa" (the constant transformation of everything)...Those factors are sophisticatedly incorporated into the arrangement, planning of the garden-house, facilitating a lasting compatibility between the house and the surroundings.

- Folk religion in constructing residential space: In the traditional Vietnamese society, there are ideologies of supernatural forces (spirits of the Heavens, earth, of ancestors) that are present everywhere, in everything, including the living space. The location, direction, time of construction of a house can influence the fate and development or downfall of those living in that house. Thus, the prospect of a family does not only depend on the effort to harmonize with the surroundings, but on spirituality as well. The inhabitants of an area have learned the correct behaviors to aegis spirit of the earth (thổ thần thổ địa) to ask for permission for settlement, to aegis spirit of the trees (via "lễ phạt mộc" - the rite of tree-cutting) for construction materials, to aegis spirit of the sky and natural phenomena such as sunlight, rain, thunder (via "lễ gài nóc" - the rite of roofing). They are natural elements that steadily influence the house-to-be. They are also the way people converse with the spirits to ask for the protection of the house and of those living in it, against the vast unknown cosmic and nature full of mysteries.

Thus, folk feng-shui, religion and spirituality that strive for the balance between "naturearchitecture-human beings" are vividly expressed in multiple occasions, indicating the close connection between the inhabitant and nature, forming a spiritual consciousness in the Vietnamese traditional residential space.

\section{Characteristics of and lessons from sustainable approaches to nature in traditional architecture}

Traditional architectures of the North, the Central and the South of Vietnam have created architectural paradigms lasting over time and space, simultaneously converting nature to benefit the inhabitant, and adapting to natural environment through self-correcting behaviors...resulting in solid values that can be applied to the residential space of a family and to each individual [9, pg. 153-155].

- Harmoniousness: Since ancient time, people have strived for a harmonious lifestyle in close relation to nature. Nature is ever-ready. Humans, on the one hand, wish to rely on nature 
for their own living, leading to a flexible lifestyle. Yet on the other hand, they always wish for the conversion of nature for their own sake.

- Suitability and profitability: Accommodation and production are organized into villages and towns, guilds and societies for their members to support one another, for collaboration to make full use of available resources, for flexibly coping with natural conditions, and for the accumulation of experience handled down to generations. Spatial arrangement via the planning of precincts and gardens is logically calculated to maximize area, whose every inch is as valuable as gold, and natural resources for the highest "self-sustaining" economic outcome, as far as geography, climate and natural environment still permit.

The adaption to and acceptance of difficulties also prove the Vietnamese people's respect for products born from labor in time of economic hardship, as well as the previous generations' awareness of moderate usage, regeneration and preservation of natural resources, with the hope for a better life for the next generations. Those are the life philosophy and noble traditions of the Vietnamese people throughout history.

- Flexibility: In the planning and arrangement of the floor and multi-functional spaces, architectural elements are designed to ensure unity and harmony with nature, and each architectural component carries in itself integration and stability. Flexibility is illustrated in the arrangement of spaces such as the main house, auxiliary houses, gardens, gates, walls, hedges...in accordance with the terrain, habit of production, living condition, family structure of each family in a village, a town in different region. This pattern of behavior signifies the humane bonds between Vietnamese traditional architecture and nature.

- Aesthetics: The distillation of aesthetic values is chiefly reflected in the history of architecture of Vietnamese people. Each material possesses unique inborn colors, yet when employed in a construction, those inborn colors merge to create various color combinations, enhancing the building's aesthetics. The refined use of nature and landscape from a wide range of angles, inside and outside the house, makes the living space more comfortable and architecture more pleasing.

Besides prominent traits, there exist numerous limits that hinder the mobility and creativity of inhabitants of a space, which call for heedful consideration and solutions.

- Impulsive, instinctive approaches and reactions to nature. In case of natural disasters, reactions are localized and passive.

- Residential spaces are often treated with cliché solutions, and experience-based and habitual approaches, which lack comprehensiveness stemming from an encompassing perspective.

- Though it has been a long time, optimal modes and solutions for deltas whose geography and climate cast constant influence on the living space are yet to be found.

The above inductions show the development of Vietnamese traditional houses, based on an organic and creative relationship with nature, indicating respect for and awareness of the protection of natural resources in the construction of residential spaces. The process has accumulated a wealth of cultural values in terms of perception and behavior with nature, architecturally aesthetic values, and expressive values in terms of religion and spirituality, integrating wisdom and experience. It also displays a rather profound understanding of nature, with flexibility, creativity and labor, gradually turning downsides into edges, misfortune into fortuity, harm into good, using nature against nature. Through the process, one can see how Vietnamese people economically and wisely utilize what is readily available in nature and what can be upgraded, in full consciousness of protecting and not overexploiting nature, to save for the next generations. Still, it poses long-lasting problems for the next generations to overcome. Such can be seen as practical lessons, immediately applicable to modern architecture, which is thriving on the foundation of scientific and technological advancements of today. 


\section{Summary of architecture and interior design training for a sustainable and ecological development}

From mid 20th century onward, there have been various trends in Ecological Design, Bioclimatic Architecture, Environmental Architecture, Energy conservation Architecture, Adaptive Architecture, Green Architecture...which belong to a greater concept of Sustainability: sustainability in ecology, environment, energy, natural resources, living environment, living space, mentality and emotion. According to a certain definition, "Sustainable design is a philosophy in the creation of physical objects, artificial living spaces, or non-material products (services) in accordance with sustainability principles." Such principles are: [13, pg. 53-54]

First, sustainable economic development.

Second, sustainable social development.

Third, sustainable environmental development.

Those principles work closely with urban planning and construction. They are the foundation for criteria for sustainable design, green design, sustainable environmental development.... and chiefly include the following points:

1. The effective use of natural resources, especially the non-renewable ones;

2. Development which does not exceed the bearing capacity of the ecology;

3. The protection of biodiversity and the ozone layer;

4. The control of and reduction in greenhouse gases;

5. The rigorous protection of vulnerable ecosystems;

6. The reduction in waste, the rectification of pollution (air, water, soil, food pollutions), the improvement and restoration of the environment in polluted areas...

From the three principles of sustainable development, one can build up criteria for the "sustainability" of a design, which designers and studies can refer to in their thinking process: Structural sustainability, Sustainability in the life cycle of a product, Health safety of the user, Preservation of cultural identity, Energy conservation in production, operation and disposal.

A sustainable design must meet those requirements so that design products can turn in economic benefits, aid in the protection of environment, cultural identity, natural resources, and in particular, the upholding of the user's health. It has been proven from reality that systems of criteria for "green" design, "ecological" design currently employed in architecture bear much resemblance to the patterns of thinking and sustainable behavior with nature in Vietnamese folk architecture and traditional architecture.

\section{Lessons from experience}

Valuable lessons in sustainable approaches to natural environment mentioned above are the foundations that we can inherit, learn from, improve to continue their strengths in the sustainable construction and growth of design and design training today. In education, it is essential to impart the awareness of the protection, conservation, respect of precious valued born of traditional architectural heritages to apply and create new values in time of trends for sustainable construction and development in every aspect of the modern life.

The bygone days of traditional architecture were hindered by many limitations and difficulties; thus, all approaches had to "wrench out the maximum from the minimal..." (Hoàng Đạo Kính, article "Green architecture - Adaptation in place of Coping", Conference, 9/2011 [1. Pg.3]). Today, to catch up the pace of urban growth, Vietnamese architecture is focusing on solutions based on scientific, technical, technological advancements in design and construction; therefore, it is advisable to learn from valuable experience of the old methods and and employ it with flexibility and improvise modern science, technique and technology in mind. 
- Behavior with soil and water should start with respect for existing topography, terraneous features of a location. The use of resources should be reasonable and wellconsidered, allowing restoration for the welfare of the next generations. The volume of an architectural building should be proportionate to the ground area, so that nature and greenery can exist and rainwater can penetrate into the soil.

- Nature should be respected. The building and house should be naturalized inside out under all possible conditions. Mutil-layered architecture can be mixed with greenery, water surface, landscape as in traditional architecture. This is especially useful when suitability is now highly valued, and the almost unchecked growth of urbanization is drying up buildings and urban areas.

- Nature should be deeply utilized in interior spaces. Existing water surface, greenery should be upgraded and enhanced with artificial farming, so that more species can be obtained and symbiosis between the plants, architecture and humans in those spaces can be achieved.

- Environmentally friendly nature-based, untreated, unheated materials that can easily adapt to varying climates and self-decompose should be maximally employed to great effect. Alternative, recycled, multi-functional materials as well as material that mix solid and empty patches, glass material, material colors... should also be considered.

- Spaces in a construction should be give correct directions and technical solutions, to prevent harsh sunlight, to let in natural light and airiness. Open spaces and flexible conditional spaces should be expanded.

- After many years of continuous growth, information technology has permeated into all aspects, habits, customs of the daily life, bringing out numerous surprising visual effects and values, both real and virtual. Accordingly, the chance to exploit automated control, multimedia effect, multi-dimensional visual effects is increasing. They are solutions for designers to transplant images and simulations of nature into architectural spaces for more aesthetic benefits.

\section{Architecture and interior design training for a sustainable and ecological development}

As time passed, Vietnamese traditional architecture with its tangible and intangible values has suffered great damage and loss, due to many reasons. To preserve and advance those values, it requires the crucial role of the people - especially those who used to and will directly carry out the duty of research, management and training of personnel in the creative field of design. The employment and application of traditional values in sustainable approaches to nature, in constructing and developing sustainably ecological environment has a significant meaning in architecture and interior training, which incorporates many tangible values and is capable of creating new values in function and aesthetics for a sustainable growth.

The curricula for theoretical subjects, aiming at conveying knowledge of sustainable and ecological architecture... is quite limited in relation to other theoretical subjects, with just few optional subjects and seminars available in the final years (semesters 8 ,9) such as Vietnamese traditional architecture 30 periods (optional), Ecological architecture 30 periods (optional), Tropical Architecture 30 periods (optional). There is no project or field trip regarding sustainable development for students to come in contact with reality, studying and utilizing it in the creative thinking process for the design.

Presently, many students have ventured into the area; yet their researches are superficial and lack practicality. Resources, information, experience from traditional architecture in course books, reference books, websites... are not enough and not interesting enough for students to approach and study. Hence, their understanding is just at an average level, 
sufficient as basic design data for school projects. Forms of and solutions for open space, material, greenery can chiefly be found in service buildings with an emphasis on visual attractiveness such as restaurants, spas, hotels...but not in public constructions. On the other hand, still neglected and unexploited are folk experience in sustainable approaches to the environment, in solutions for interior and exterior spaces, architectural shell. Such wisdoms can create new values of sustainability, suitable for economic, cultural conditions, mentality, habits of usage of the Vietnamese people in architectural and interior spaces. They should become a pattern of thinking, targets, destinations of the young generation in creative and design thinking, on the foundation of and with the criteria for functional and aesthetic sustainability.

In recent years, there have been a number of topics and graduation projects of the Faculty of Architecture and Interior Design, as well as criteria for contests, awards in interior design concerning criteria in sustainable and public design...As a result, many students, under the guidance and encouragement of instructors, have approached and employed solutions, forms, design language... relating to ecological and sustainable design for their design proposals. They have initially made good impressions for their forms and solutions that adapt to climatic conditions, utilize local materials, achieving sustainable and ecological design...Such are good signs in the training environment of future designers.

\section{Graduation projects of students from the faculty of architecture and interior design, Ho Chi Minh City University of Architecture}
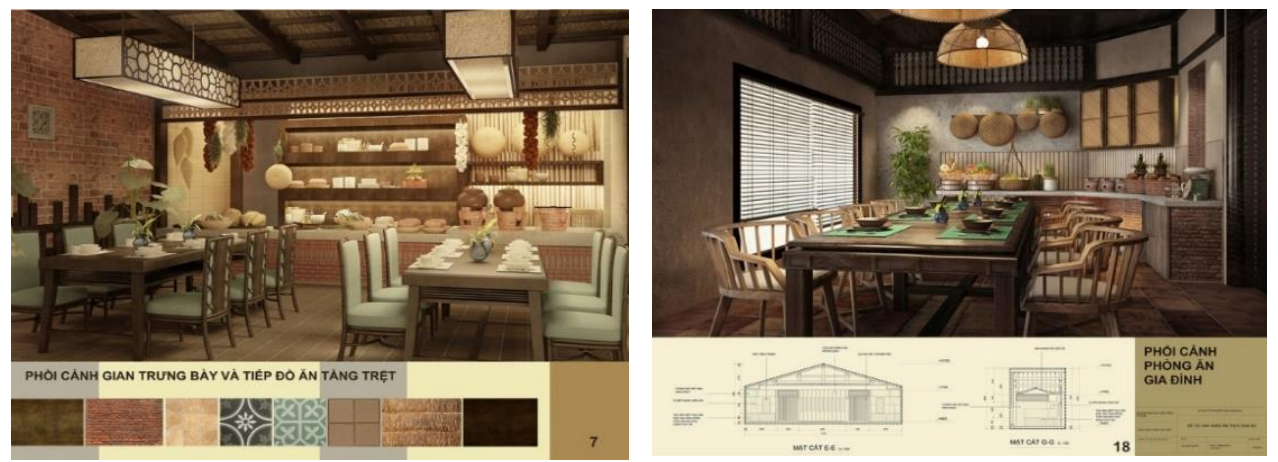

Fig. 3. Original natural materials with local nuances, Graduation Project: "Southern Cuisine Restaurant", student Lê Thúy Quỳnh, NT09.
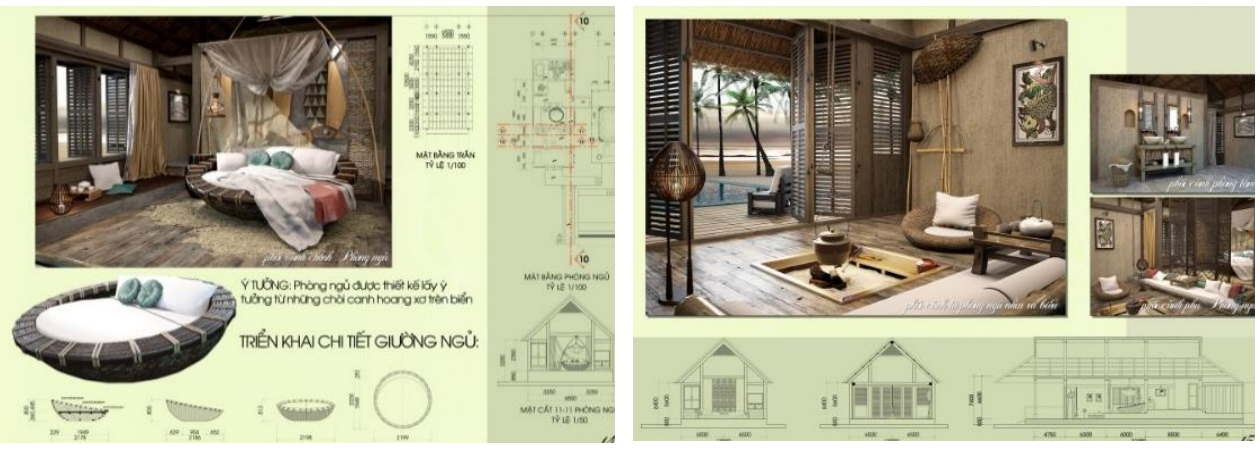

Fig. 4. Original natural materials from local sources, open spaces with natural landscape and ventilation, Graduation Project: "Phú Quốc Starlight Resort”, Nguyễn Thị Ánh Linh, NT08. 

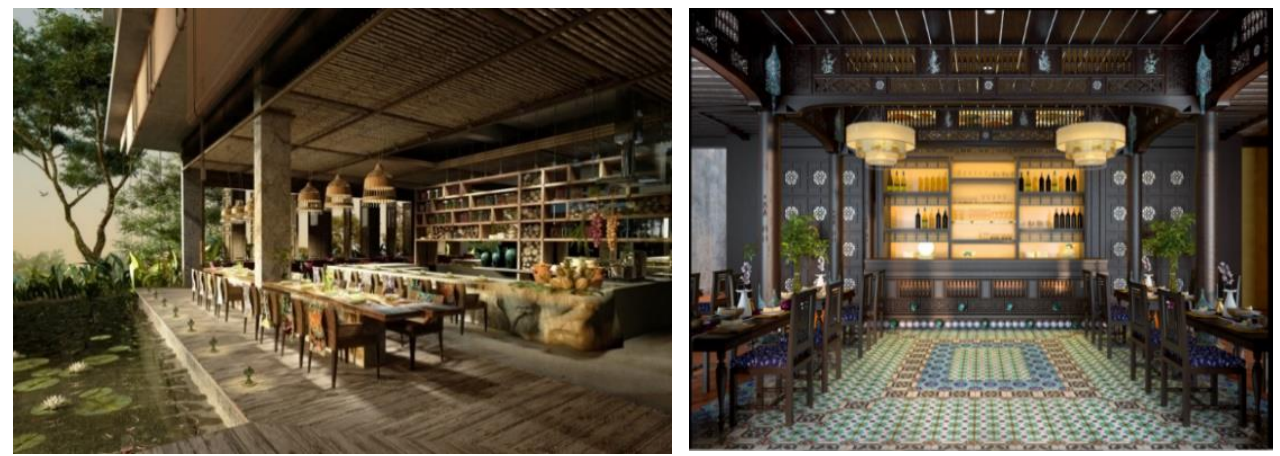

Fig. 5. Open spaces with the employment of water surface, natural lighting and ventilation, Graduation Projects of student Nguyễn Thị Thanh Hằng, NT07 and "Thừa Thiên-Huế Tourism Center" of student Hoàng Thị Kim Phương, NT10. (Sources: authors).

\section{Proposals}

The calling of the university is the training of young generations for the understanding, inheritance and development of values of sustainable development in the career. The next step is the awareness of the role and responsibility of a future designer in learning and creating. For such tasks, we would like to present some proposals:

- Architecture and interior design training should emphasize more on technical and ecologically sustainable material solutions, to facilitate teaching staff to research, build up teaching materials, material libraries in a professional way, to serve the training of specialized personnel for projects, establishments, and agencies active in related fields.

- Strengthening subjects on architecture history, geography, culture....as fundamental subjects. Reports, essays and mini-researches should be more popular, to help students look for sustainable design solutions and concepts before they work on style and appearance...; as a result, rote learning can be avoided. The teaching staff should commend and encourage students' scientific researches, school projects...that exploit sustainable development values, regarding them as goals for learners in the instruction of subjects and practice of projects. Instructors should also provide greater support to students.

- Organizing conferences, exhibitions, workshops...as a chance for students, departments, faculties, schools to exchange information with experts and associations in green, sustainable architecture. Information on such cases should be widely spread over the information systems and websites. Students should have more opportunities to go on field strips, directly participate in local projects, public constructions involving sustainable development, in order to create an academic and a sense of responsibility in students, who need to contribute to the process of ecological and sustainable development in their learning and career.

- Affiliating with design associations from foreign and national universities for students and teaching staff to exchange information about and get updated with new standards and technologies in this international trend of sustainable construction, development, green design. Experienced inviting professors and experts should be more asked for, as to build up teaching staff with high qualifications and devotion, much needed in the "esoteric" training environment of the University of Architecture.

Sustainable development is a critically important subject that should be taken seriously by the Government and ministries, as to plan and draw up strategies, take up responsibility in their respective expertise. Knowledge and constructiveness cannot be isolated from this macroscopic situation. For which the training of personnel is paramount, in order to nourish 
young academicians with awareness, understanding, well-equipped with knowledge to inherit and develop values of sustainable development, as means to further their future career.

\section{Reference}

1. N. H. Côn, Architecture and Biome (Construction Publishing House, Hanoi, 2004)

2. P. Đ. Nguyên, Bio-climatic Architecture (Construction Publishing House, Hanoi, 2010)

3. H. Đ. Kính, Architectural Culture (Knowledge Publishing House, Hanoi, 2012)

4. L. T. Nhân, Feng Shui landscape and interior architecture applied in Vietnam (Times Publishing House, Hanoi, 2011)

5. J.F. Mc Lenan, Philosophy of Sustainable Design: Future of Architecture (Ecotone, Kansas City, 2004)

6. T. Williamson, Understanding Sustainable Architecture (Spon Press, New York, 2002)

7. Lê Bá Thảom, Nature of Vietnam (Education Publishing House, Hanoi, 1997)

8. Hoàng Huy Thắng, Humid Tropical Architecture (Construction Publishing House, Hanoi, 2002)

9. T.T.T. Võ, The Culture of Approaches to Nature in the Living Space of Vietnamese People (Doctoral thesis, 2013)

10. Đ. T. Nguyễn, Architecture of Vietnam through the ages (Publishing House, Construction, Hanoi, 2002)

11. Institute of Tropical Architecture, Tropical Architecture of Vietnam - Orientations and Solutions (First National Scientific Conference, Hanoi, 2005)

12. Institute of Tropical Architecture, Architectural Development in Relation to Strategies for Environment Protection and the Program for Using Energy Economically and Effectively (National Science Conference, 2008)

13. Institute of Tropical Architecture, Green Architecture - Future Architecture (Summary Record of National Science Conference, 2011)

14. The Government's Decision No. 432/QĐ-TTg: Approval of Strategies for Sustainable Development in Vietnam for the Period 2011 - 2020. 